\title{
Les oléoprotéagineux dans les systèmes de culture : évolution des assolements et des successions culturales depuis les années 1970 dans le bassin de la Seine
}

\author{
Céline SCHOTT ${ }^{1}$ \\ Catherine MIGNOLET ${ }^{1}$ \\ Jean-Marc MEYNARD ${ }^{2}$ \\ ${ }^{1}$ UR 055 ASTER-Mirecourt, \\ 662 , avenue Louis-Buffet, \\ 88500 Mirecourt, \\ France \\ <schott@mirecourt.inra.fr> \\ ${ }^{2}$ Département SAD, INRA, \\ 78850 Thiverval-Grignon, \\ France
}

\begin{abstract}
For the last forty years oilseed and high-protein crops have undergone important changes in terms of area and localisation in France. On the Seine basin example, we show that the specialisation of the farming systems and the agricultural regions has strongly changed the cropping patterns by reducing grasslands which were replaced by a constant increase of the wheat area in a one hand and by a dramatic increase, from the eighties, of the rapeseed, field pea and sunflower areas in another hand. Then from the nineties, rapeseed has gradually replaced field pea and sunflower, the areas of which have fallen. The decrease in the number of cultivated species has led to a clear trend to the simplification and the shortening of the crop successions: short crop successions based on rapeseed (as rapeseedwheat-barley or rapeseed-wheat-wheat) and cereal successions (as wheat-wheat-wheat, wheatwheat-barley or wheat-barley-barley) have strongly increased on the Seine basin over the last twenty years. The crop succession shortening, that causes crop protection problems towards weeds, insects or diseases, is only possible in relation with an intensive use of pesticides: thus the increase of the rapeseed area is positively correlated with the increase of the average number of plant pest controls, especially with herbicides. These agricultural dynamics have negative impacts on environment and enhance the economical risks the farms have to cop with. As a consequence, a new crop diversification, supported by policy-making and agricultural production networks, seems to be a strong future issue.
\end{abstract}

Key words: cropping system, crop succession, long term evolution, agricultural specialisation, crop diversification
Les oléagineux et les protéagineux n'ont pas toujours occupé la place qu'on leur connaît aujourd'hui dans les systèmes de culture français. Depuis 40 ans, ils ont été l'objet de fortes variations de surface mais aussi de processus de relocalisation au sein du territoire métropolitain qui font que les régions agricoles dans lesquelles ils sont actuellement cultivés ne sont pas forcément les mêmes que dans les années 1970. Les variations et relocalisations des surfaces en oléoprotéagineux ont contribué au développement d'une grande diversité de successions culturales qui ont évolué au cours du temps, dans lesquelles ils sont associés, avec des délais de retour variables, à des céréales ou d'autres cultures industrielles ou fourragères. L'objectif de cet article est de caractériser, sur les 40 dernières années, les processus de relocalisation des surfaces en oléagineux et protéagineux ainsi que l'évolution des successions culturales dans lesquelles ils ont été insérés, en rappelant les facteurs majeurs qui les ont déterminés.

Nous illustrons ce propos sur le territoire du bassin versant de la Seine qui s'étend sur 23 départements du nord de la France, couvrant une superficie de $95000 \mathrm{~km}^{2}$ (figure 1). En 2000, le bassin de la Seine compte 102000 exploitations agricoles qui représentent $15 \%$ des exploitations françaises et $23 \%$ de la surface agricole utile (SAU). Quarante-cinq pour cent des surfaces en blé et $80 \%$ des surfaces en betterave françaises y sont concentrées. Plus de la moitié de la surface du bassin est occupée par des terres labourables, ce qui en fait la principale région de production de grandes cultures en France. Cette situation fait suite à plusieurs décennies de mutations profondes des activités agricoles, qui ont bénéficié de progrès techniques sans précédent tout en étant encadrées et pilotées par les marchés et leurs impératifs économiques ainsi que par la réglementation européenne qui s'impose à partir des années 1960 . Toutefois, ces mutations ne se sont pas produites de manière homogène sur l'ensemble du bassin, au sein duquel persistent des disparités tant géographiques qu'économiques (Mignolet et al., 2007 ; Schott et al., 2009).

Pour analyser la place des oléoprotéagineux dans l'évolution des systèmes de culture du bassin de la Seine, nous mobilisons plusieurs sources d'informations complémentaires issues du service de la statistique et de la prospective (SSP) du ministère de I'Agriculture: les recensements agricoles de 1970, 1979, 1988 et 2000 produisent des informations exhaustives sur les assolements; l'enquête nationale "Teruti », conduite annuellement sur un échantillon constant de points répartis sur le territoire national (de 1992 à 2003 puis de 2006 à 2009), permet de reconstituer les successions de cultures et leur évolution; enfin, l'enquête "Pratiques culturales ", réalisée en 1994, 2001 et 2006 sur un sous-échantillon de l'enquête "Teruti», décrit les itinéraires techniques pratiqués sur grandes cultures, permettant en particulier de caractériser l'évolution de l'usage des pesticides.

L'article est composé de deux parties. La première décrit les grands traits de l'évolution des assolements dans le bassin de la Seine depuis les années 1970, en replaçant l'évolution des surfaces en oléagineux et protéagineux dans un cadre global. La seconde partie est centrée sur l'évolution des systèmes de culture illustrée par l'évolution des successions culturales et par l'évolution des pratiques phytosanitaires qui l'accompagne. Nous conclurons sur quelques réflexions concernant l'évolution future des systèmes de culture et des enjeux associés. 


\section{Grands traits de l'évolution des assolements dans le bassin de la Seine}

\section{Spécialisation des régions d'élevage et de culture}

Entre 1970 et 2000, I'assolement du bassin de la Seine subit des changements de grande ampleur, au premier rang desquels figure la chute d'un tiers des surfaces en prairies permanentes. Les prairies, supports des activités d'élevage de ruminants, sont encore bien présentes en 1970, hormis en Champagne crayeuse et en Beauce, où elles représentent moins de $10 \%$ de la SAU (figure 2). Depuis cette période, la baisse des surfaces en prairies est continue, jusqu'à une quasi-disparition dans toute la partie centrale du bassin. Les surfaces en herbe se concentrent sur les bordures sud-est (Morvan, Auxois), nord-est (Ardennes) et ouest (Basse-Normandie) du bassin, dans des régions d'élevage spécialisées où elles occupent plus de $50 \%$ de la SAU. Dans la plupart des régions d'élevage, la diminution des surfaces en herbe est en partie compensée par la progression du maïs fourrage (figure 3), moyennant souvent des aménagements tels que le drainage. Cette progression du maïs fourrage est particulièrement marquée dans les années 1980, puis dans les années 1990 en Normandie et dans les Ardennes, en relation avec l'intensification de la production laitière et le développement d'ateliers d'engraissement de jeunes bovins.

À l'inverse des prairies, le blé tendre est présent sur l'ensemble du bassin suivant un gradient croissant de la périphérie vers le centre (figure 4). Ses surfaces sont en constante augmentation depuis 1970 (+ $52 \%$ en 30 ans), marquant la prééminence des grandes cultures dans une partie croissante du bassin. En 2000, seules les régions du Morvan, des Ardennes et le Pays d'Auge de Basse-Normandie gardent des surfaces en blé inférieures à $15 \%$ de leur SAU, alors qu'elles sont supérieures à $35 \%$ sur plus de la moitié du bassin jusqu'à atteindre $45 \%$ en Beauce et dans certaines régions agricoles de l'Oise et de la Seine-et-Marne.

Ces évolutions fortes d'assolement traduisent une spécialisation des régions agricoles: concentration des activités d'élevage dans les régions les moins propices à la culture ; « céréalisation » croissante de la majeure partie du bassin. Cette spécialisation visible des assolements est confirmée par l'analyse de l'évolution des systèmes de production agricoles marquée par une augmentation constante des systèmes de production de grandes cultures, orientés soit vers la production de céréales et oléoprotéagineux, fortement dépendante des aides de la PAC, soit vers la production de cultures industrielles à plus forte valeur ajoutée (betterave, pomme de terre, légumes, etc.) (Mignolet et al., 2001).

De nombreux facteurs, tant politiques, économiques et techniques qu'humains, sont à l'origine de cette spécialisation des régions d'élevage et de culture. Le soutien des prix du blé et de certaines grandes cultures, relayé par les primes à l'hectare de céréales et d'oléoprotéagineux en 1992, la diminution de la main$d^{\prime} œ u v r e$ agricole et la recherche d'une moins grande pénibilité du travail expliquent le recul généralisé des activités d'élevage dans le centre du bassin de la Seine et leur concentration dans les régions moins favorables aux grandes cultures. La spécialisation régionale des productions est accentuée par la concentration des industries de transformation (la localisation des productions à proximité des usines et la concentration des usines dans les zones favorables à la production réduisent les coûts de logistique). Les évolutions techniques poussent, elles-mêmes, à la spécialisation régionale : pour toutes les productions, un conseil technique de plus en plus pointu devient

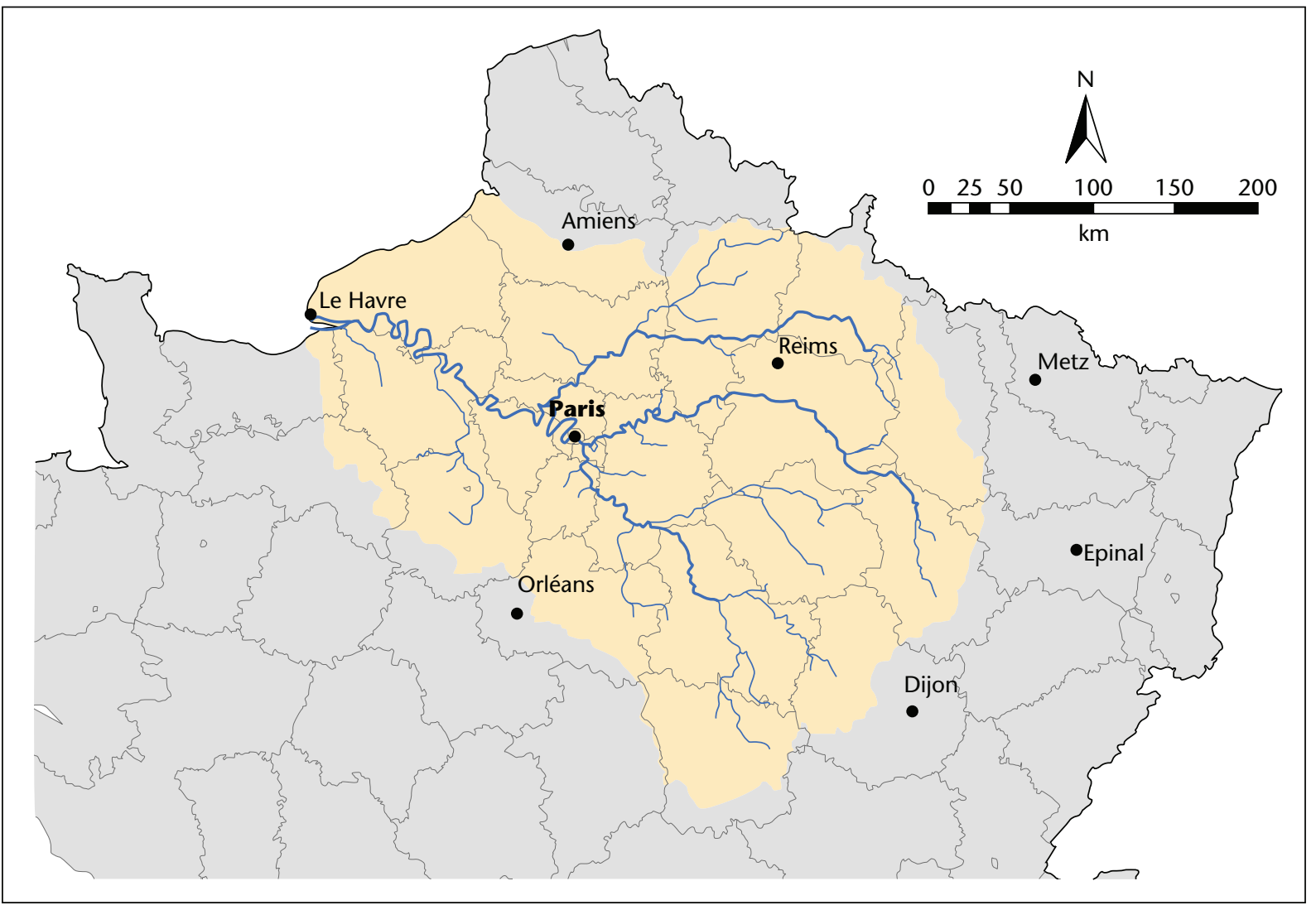

Figure 1. Le bassin versant de la Seine. 


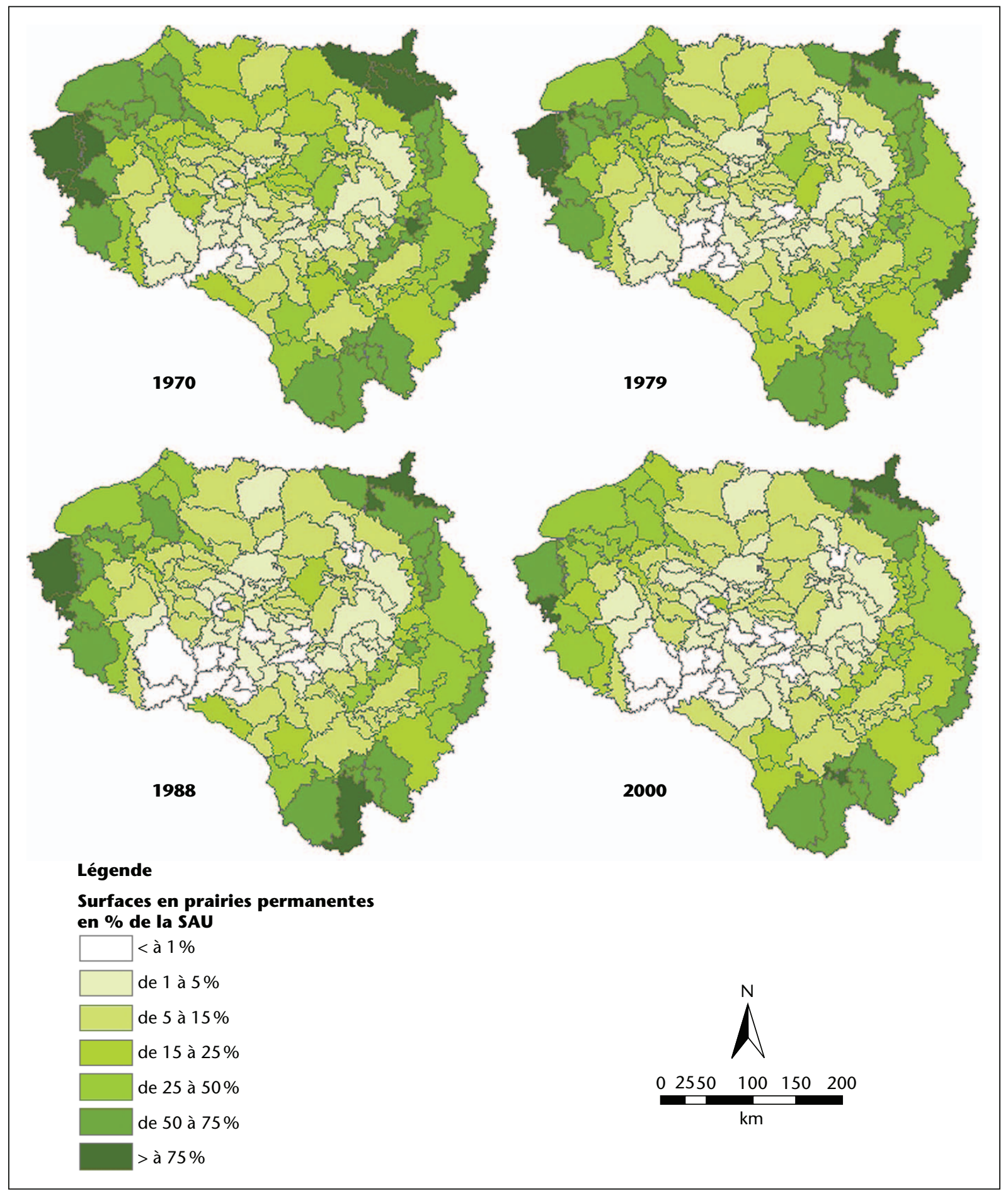

Figure 2. Évolution des surfaces en prairies permanentes entre 1970 et 2000 (source : RGA).

nécessaire, qui est souvent moins accessible pour les agriculteurs dans les régions où la production concernée est peu présente.

Cette spécialisation agricole pose en elle-même des problèmes écologiques. Dans les régions où l'élevage disparaît, le remplacement des prairies par des cultures annuelles entraîne une perte de biodiversité et une réduction de la diversité des habitats. Les zones humides drainées ont vu leur surface multipliée par 4 en 30 ans, passant de $3 \%$ de la SAU du bassin en 1970 à $12 \%$ de la SAU en 2000 . Le faible recyclage des éléments minéraux $(N, P, K$, etc.) dans les exploitations agricoles spécialisées conduit à un gaspillage de ressources non renouvelables : les éléments minéraux épandus dans les régions céréalières transitent vers les zones d'élevage via les aliments du bétail, où 


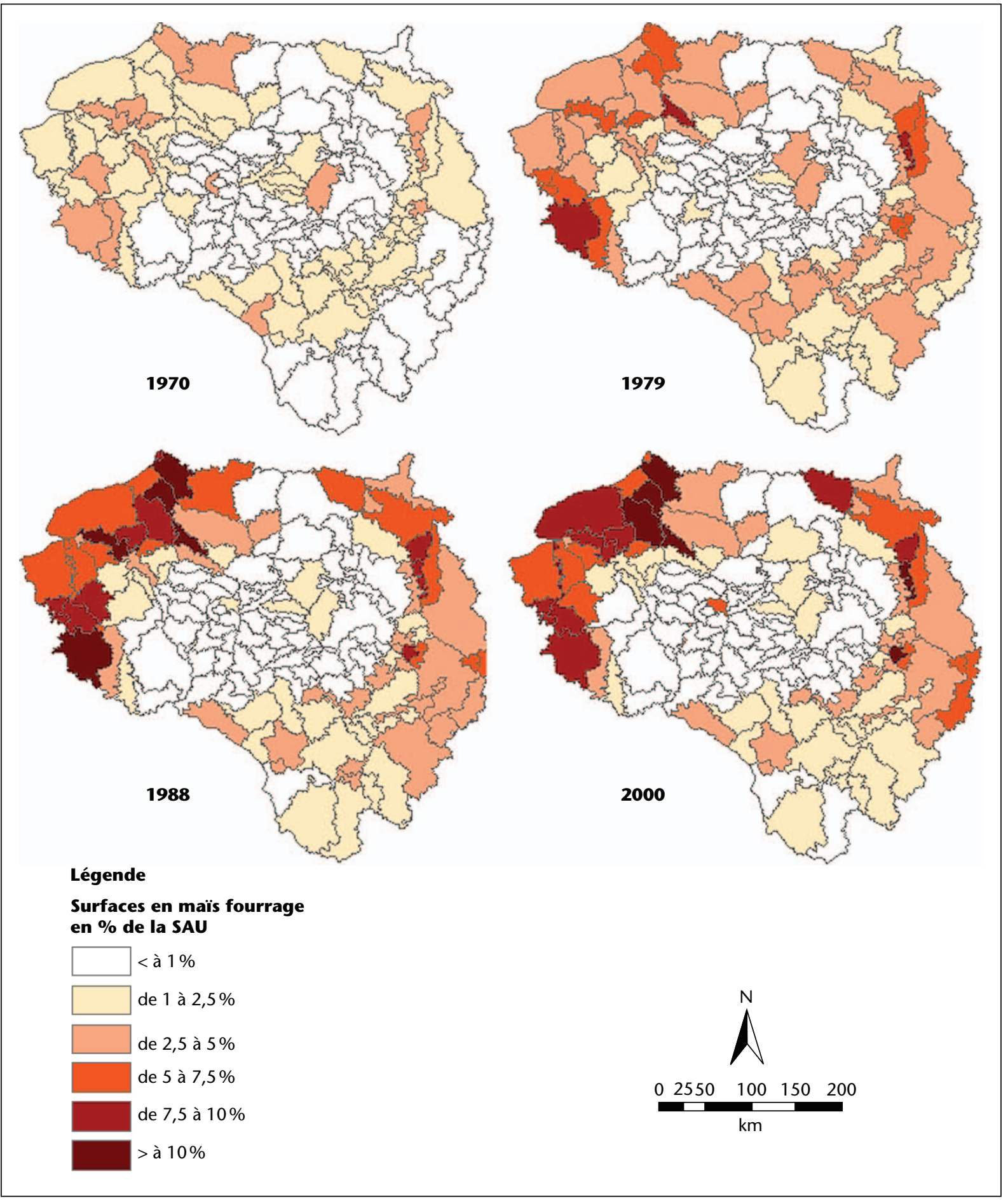

Figure 3. Évolution des surfaces en maïs fourrage entre 1970 et 2000 (source : RGA).

ils contribuent à polluer les eaux. Enfin, la contamination des ressources en eau souterraines et superficielles par les pesticides s'aggrave dans la quasi-totalité des rivières et des masses d'eau du bassin, atteignant parfois des seuils critiques dans les régions spécialisées en grandes cultures (Schott et al., 2009).
Recul des espèces végétales liées à la polyculture élevage

L'évolution de la localisation de la production de luzerne apparaît particulièrement emblématique du déclin des exploitations de polyculture élevage dans le bassin de la Seine. En 1970, la luzerne est présente sur l'ensemble du territoire et en général autoconsommée par le bétail dans les exploitations où elle est cultivée, avec des surfaces pouvant atteindre par endroits 10 à $15 \%$ de la SAU (figure 5). Trente ans plus tard, ces surfaces ont chuté de $74 \%$ et ne représentent plus que $1,5 \%$ de la SAU du bassin (mais 


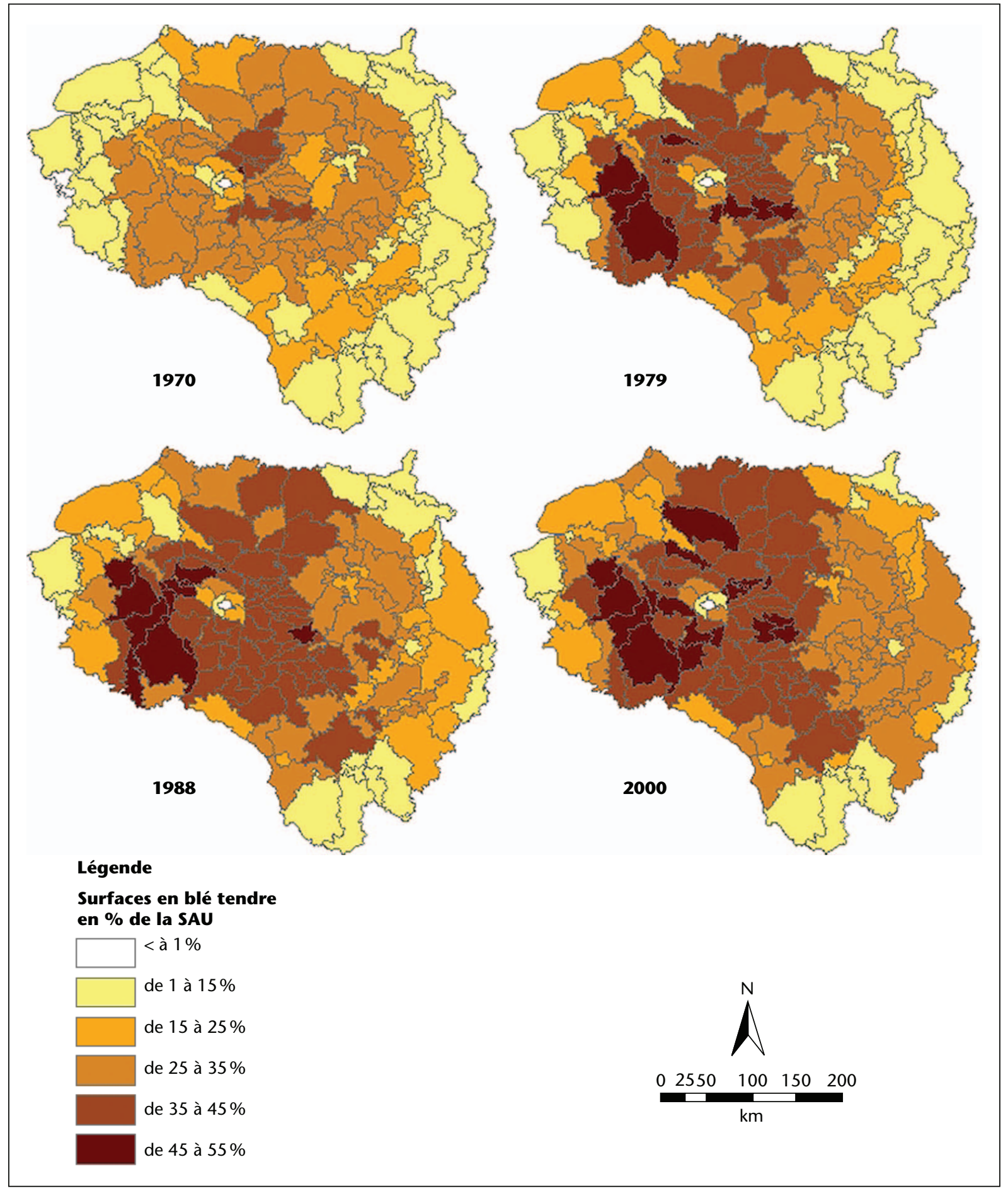

Figure 4. Évolution des surfaces en blé tendre entre 1970 et 2000 (source : RGA).

encore $27 \%$ des surfaces françaises). La luzerne s'est progressivement concentrée en Champagne crayeuse dont les sols calcaires à forte réserve hydrique sont favorables à une production élevée, encourageant l'implantation d'usines de déshydratation : la luzerne y est déshydratée grâce à l'énergie fossile pour être facilement conservée et transportée sous forme de bouchons, puis incorporée dans les aliments du bétail vendus aux éleveurs des régions spécialisées en élevage. Les années 2000 connaissent un déclin de cette filière énergivore, lié à la hausse du prix de l'énergie, à la baisse du soutien européen et à la concur- rence du tourteau de soja venu du continent américain.

Dans une moindre mesure, les surfaces en orge d'hiver, également traditionnellement cultivées pour l'alimentation animale dans les exploitations de polyculture élevage, ont décliné sur le bassin de la Seine. Ce déclin 


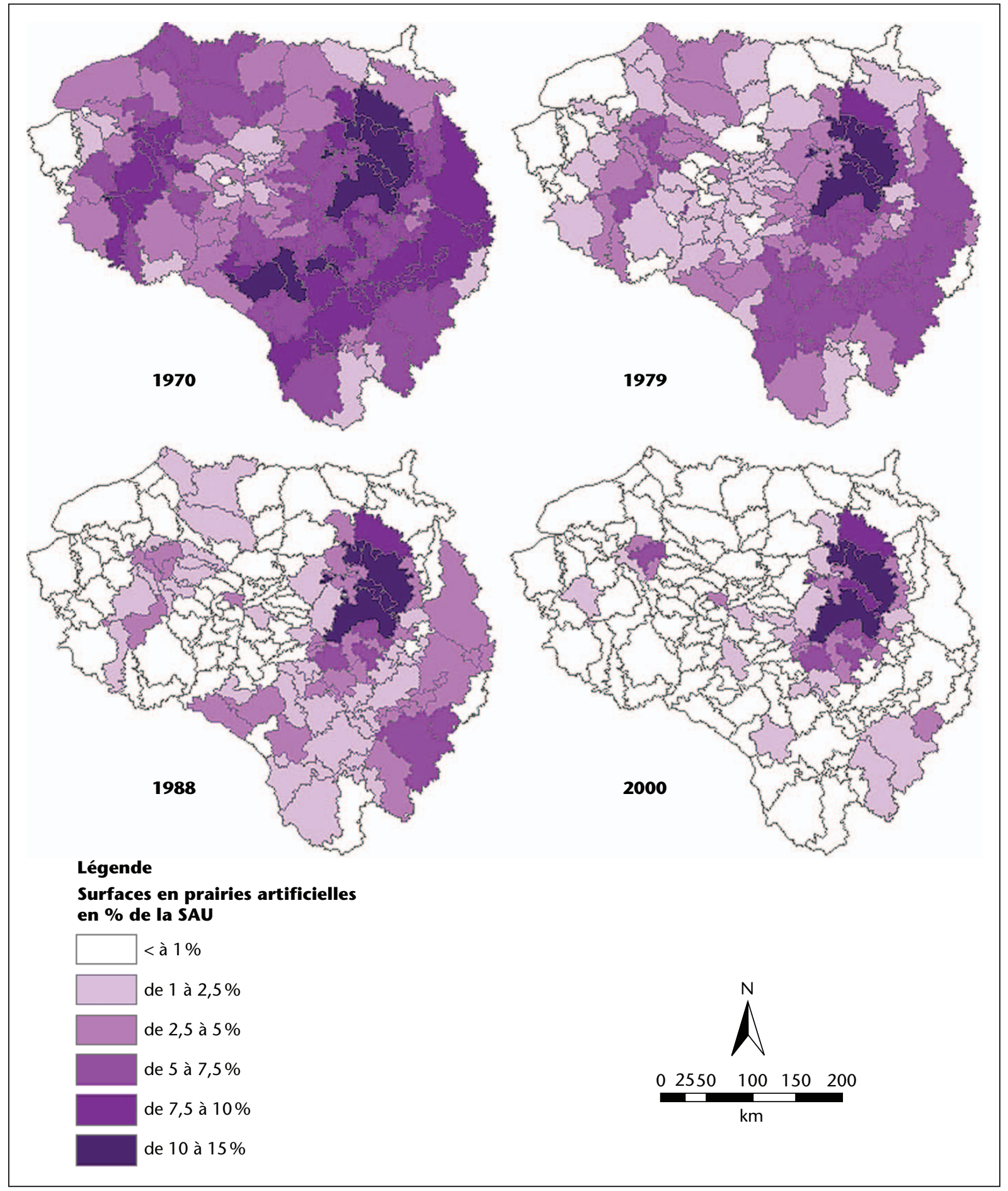

Figure 5. Évolution des surfaces en prairies artificielles entre 1970 et 2000 (source : RGA).

intervient d'abord dans les régions centrales qui, en se spécialisant dans les grandes cultures, l'ont remplacée par le blé, plus productif et rémunérateur, puis dans les régions périphériques, hormis dans les plateaux du Barrois en bordure est du bassin où elle reste bien adaptée aux conditions de sol.
Oléagineux et protéagineux :

un développement considérable dans les zones de grande culture

Dans ce contexte de spécialisation des régions de culture, les surfaces en colza, en pois protéagineux et, dans une moindre mesure, en tournesol se développent de manière parfois spectaculaire à partir des années 1980, au détriment des céréales secondaires (orge, seigle, avoine), du maïs grain (figure 6) et de la luzerne. Le colza s'étend d'abord aux régions périphériques de l'est du bassin où ses surfaces sont multipliées par 3, voire 4, en 30 ans, puis 


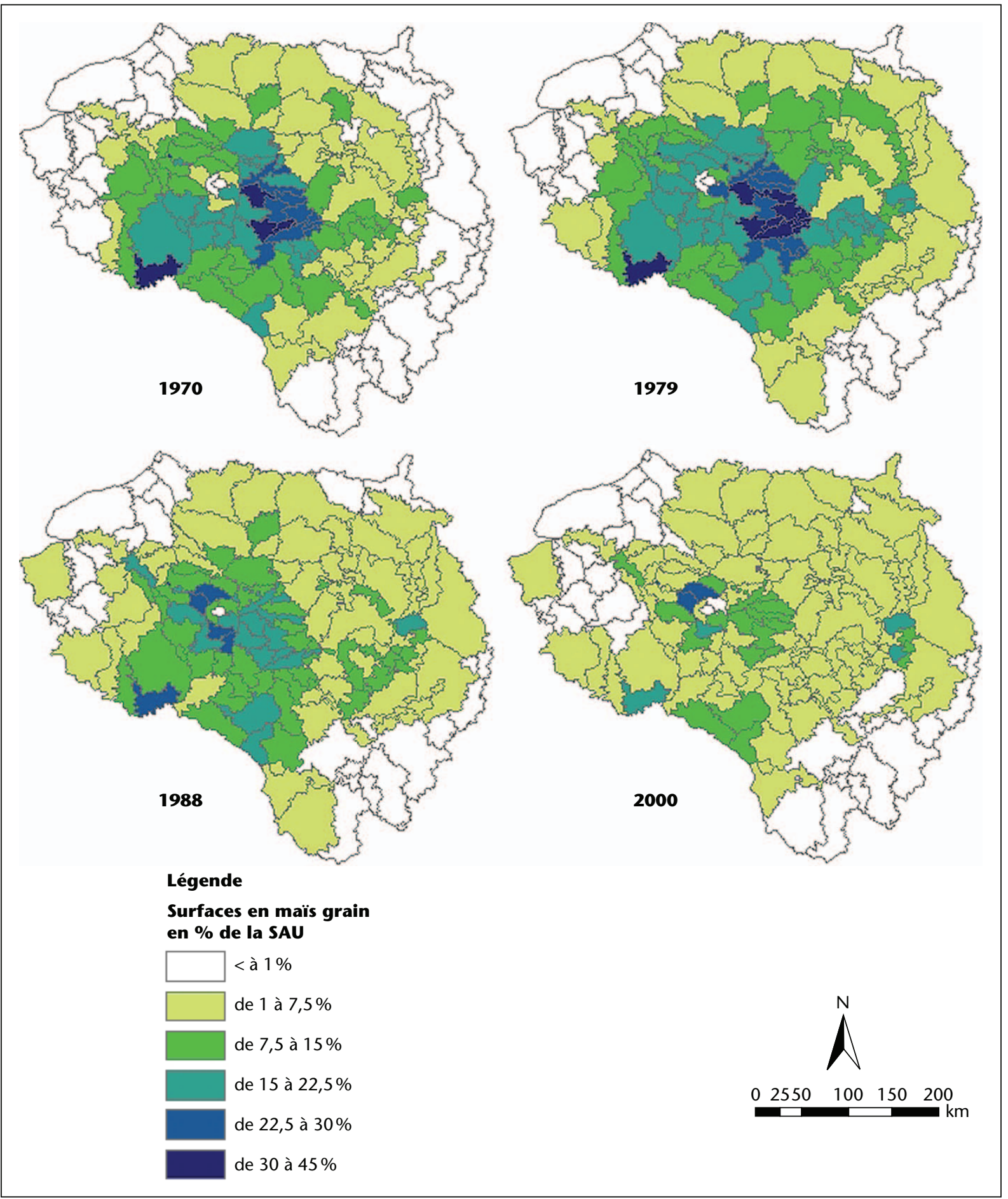

Figure 6. Évolution des surfaces en maïs grain entre 1970 et 2000 (source : RGA).

dans certaines régions céréalières du centre du bassin telles que la Beauce et ses régions limitrophes (figure 7). Avec le développement de la filière « agrocarburant ", la possibilité de cultiver du «colza diester » sur les surfaces en « jachère industrielle » des exploitations offre de nouveaux débouchés: en 2000, un tiers des surfaces en colza du bassin est destiné à la production de diester. L'essor du colza se confirme dans les années 2000, où il devient la principale culture tête de rotation dans la plupart des régions agricoles.

Le pois protéagineux connaît la même progression spectaculaire que le colza dans les années 1980 mais dans des zones différentes (figure 8) : il dépasse $10 \%$ de la SAU en 1988 à l'ouest du bassin ainsi qu'en Champagne crayeuse et dans la majeure partie de la Brie en Seineet-Marne. Toutefois, à l'inverse du colza, ces surfaces diminuent dans les années 1990, en raison de l'irrégularité des rendements, de problèmes phytosanitaires (Aphanomyces) et d'une diminution des aides après 1995. Le tournesol suit la même progression à partir 


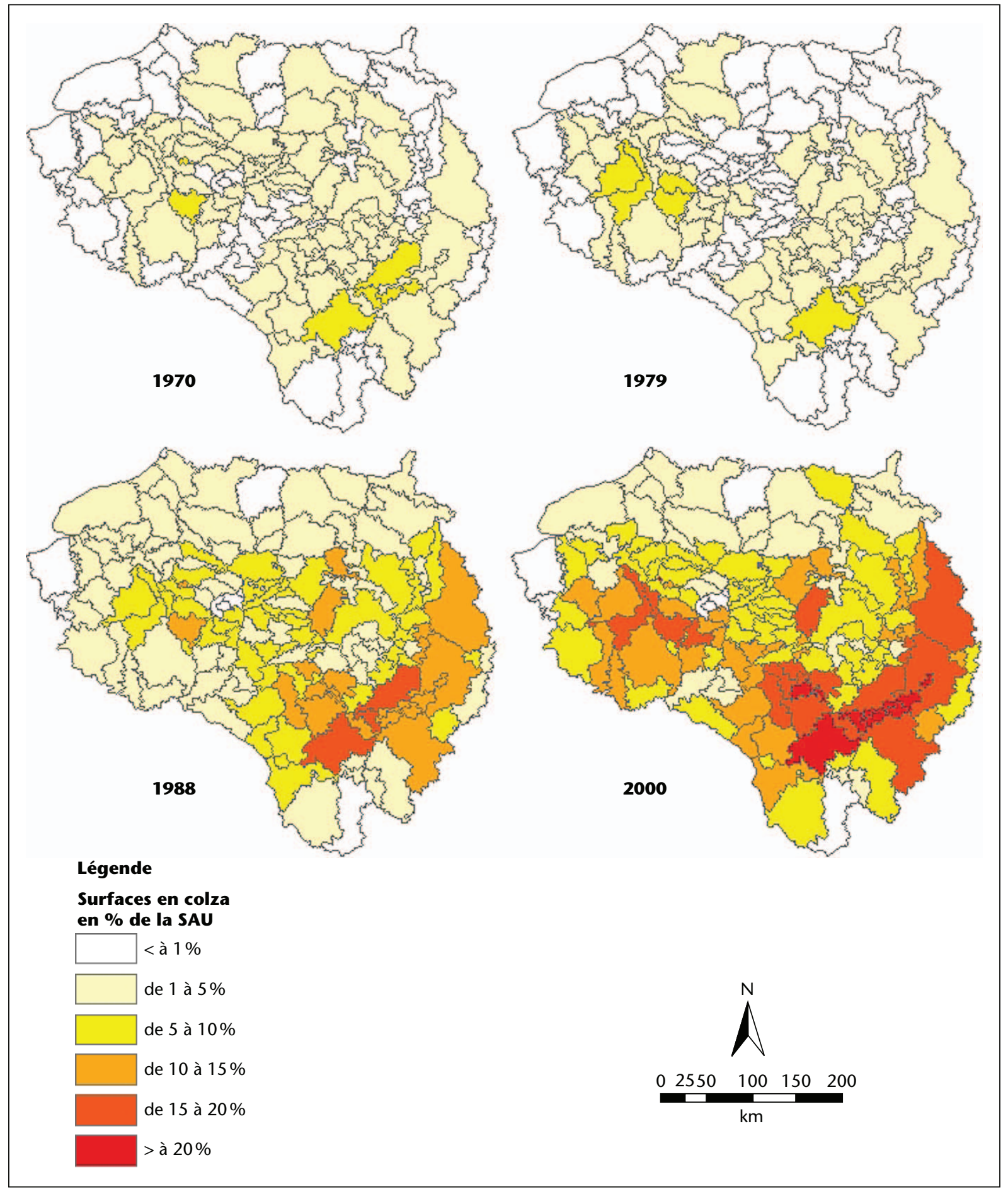

Figure 7. Évolution des surfaces en colza entre 1970 et 2000 (source : RGA).

des années 1980, en restant concentré dans le sud du bassin en raison des exigences climatiques de la culture (températures élevées et faible humidité au moment de la récolte) (figure 9). À cette période, colza, pois protéagineux et tournesol se développent donc de manière concomitante, mais les trois cultures ne sont pas antagonistes, car leur développe- ment se localise principalement dans des zones différentes du bassin de la Seine. Ce n'est qu'à partir des années 1990 que le colza remplace progressivement le pois et le tournesol dont les surfaces chutent.

Les variations de surface des principales occupations du sol agricoles du bassin de la Seine depuis 1970 sont synthétisées sur la figure 10, sur laquelle sont également indiquées les surfaces obtenues d'après I'enquête Teruti en 2009. Les surfaces en colza semblent poursuivre leur progression entamée il y a 30 ans, alors que la régression des surfaces en pois protéagineux se confirme et que les surfaces en blé semblent se stabiliser. 


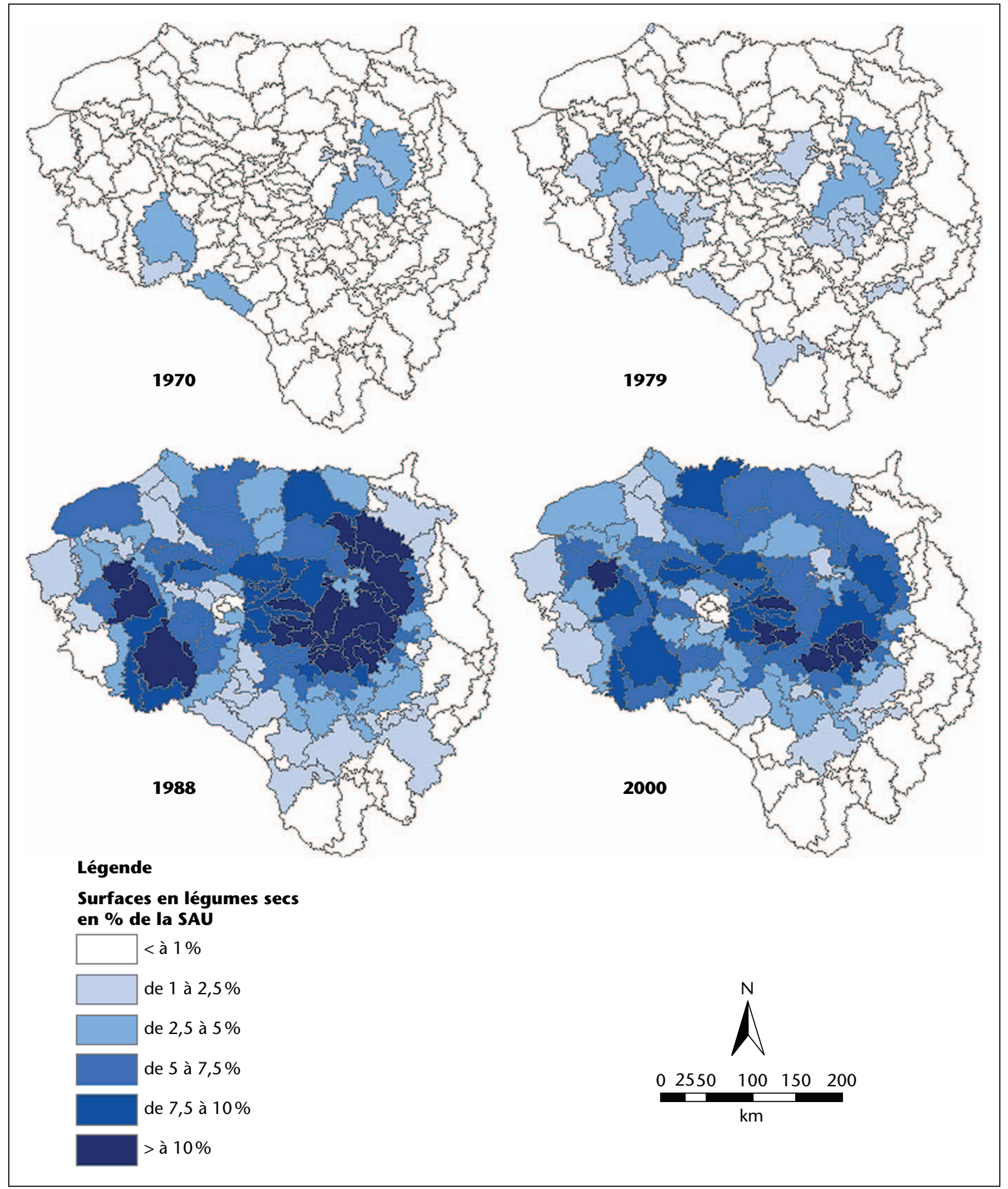

Figure 8. Évolution des surfaces en pois protéagineux entre 1970 et 2000 (source : RGA).

\section{Évolution des successions culturales du bassin de la Seine}

Diversité des successions de cultures selon leur localisation dans le bassin

Les successions culturales des régions agricoles du bassin de la Seine ont été décrites sur la période 1992-2003, en appliquant des algorithmes de fouille de données temporelles à l'enquête Teruti (Mignolet et al., 2004 ; Le Ber et al., 2006). La figure 11 montre un exemple de diagramme (nommé diagramme de Markov) construit sur la région du Barrois en Lorraine et en Haute-Marne représentant, au pas de temps annuel (axe horizontal), les probabilités de transition entre des cultures annuelles ou des prairies (permanentes, temporaires ou artificielles). Plus le trait reliant la culture $A$ de l'année $n$ et la culture $B$ de l'année $n+1$ est épais, plus la probabilité qu'A soit suivie par $B$ est élevée. Aucun trait ne relie $A$ à $B$ si cette probabilité est inférieure à $2 \%$. En plus des prairies permanentes en légère diminution, 


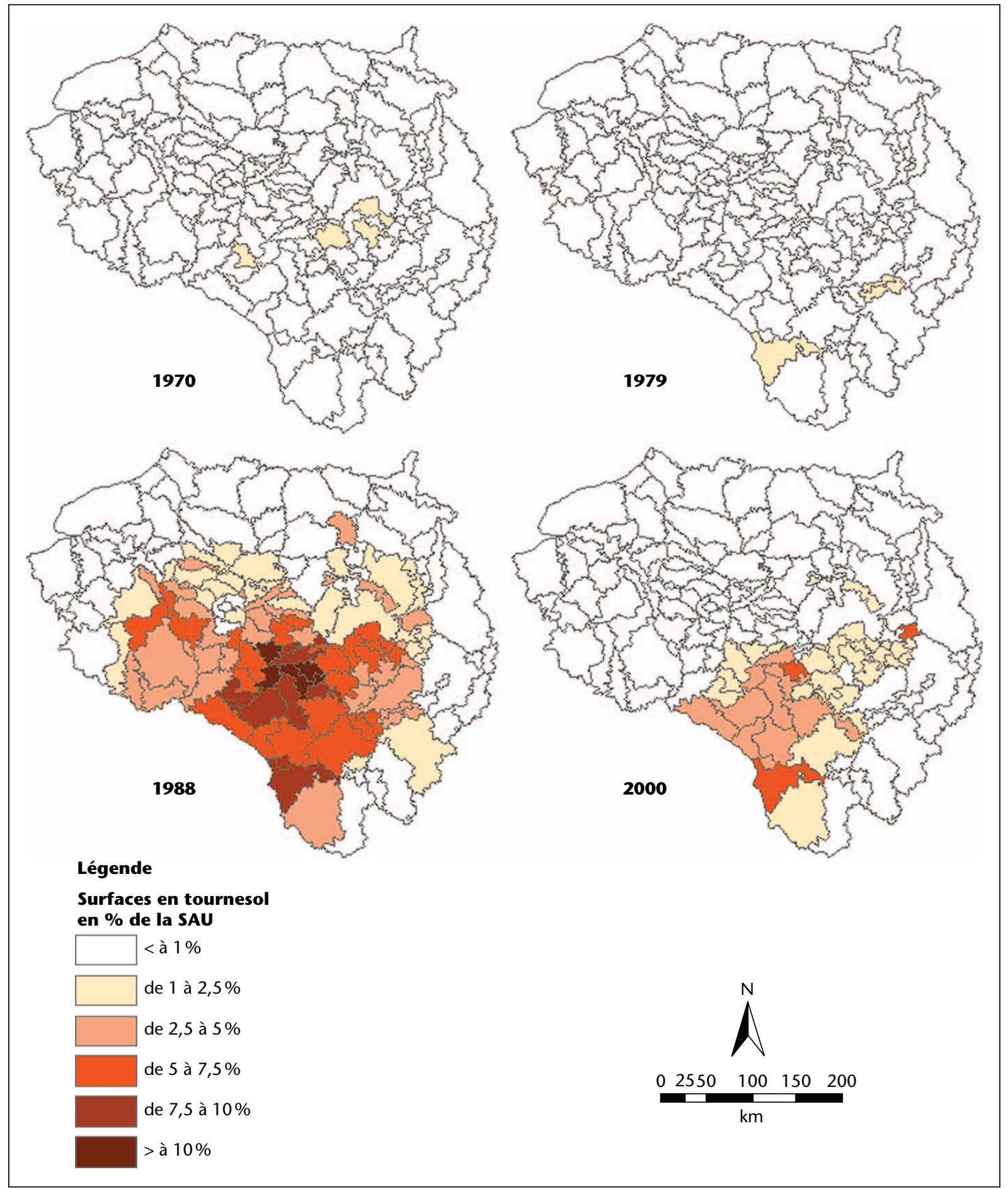

Figure 9. Évolution des surfaces en tournesol entre 1970 et 2000 (source : RGA).

une succession culturale majoritaire apparaît sous une forme triennale de type colzablé-orge, dont la fréquence s'accroît entre 1992 et 2003. Entre 1994 et 2001, elle côtoie une succession plus courte de type colzablé-colza-blé ainsi que la culture du blé sur blé pendant au moins deux années de suite. Les suc- cessions culturales apparaissent plus diversifiées dans d'autres régions, comme le Plateau picard et le Vexin (figure 12) : autour de la culture du blé s'articulent les cultures de la betterave, du pois (en diminution sur la période considérée), du maïs, du colza et de l'orge. Une grande diversité de successions culturales peut ainsi être déduite sous la forme «tête de rotationblé-tête de rotation-blé » ou sous la forme «tête de rotation-blé-orge ». Cependant, en dépit de cette diversité de cultures, la fréquence de retour du blé sur deux années consécutives augmente de manière importante (épaississement du trait horizontal « blé »). 


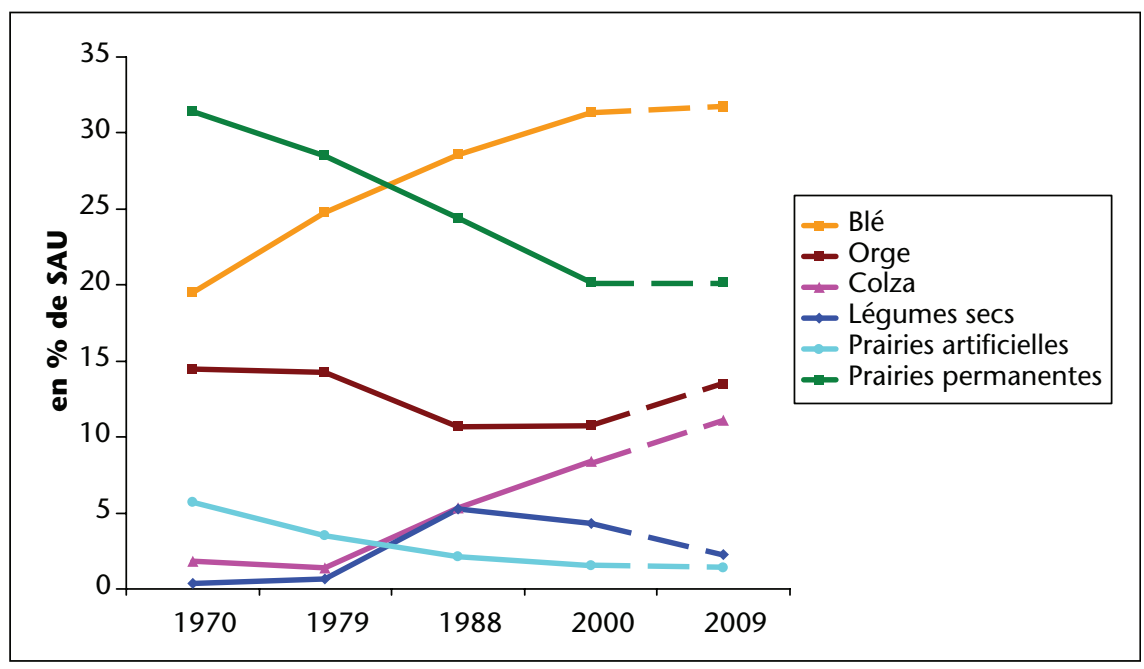

Figure 10. Synthèse de l'évolution des principales occupations du sol du bassin de la Seine entre 1970 et 2009 (source : RGA et enquête Teruti 2009).

\section{Simplification et raccourcissement des successions culturales}

Malgré cette complexité apparente des successions culturales du bassin, l'analyse des suites de cultures sur trois années consécutives (que nous nommons «triplets de cultures ») pratiquées sur les périodes 1992-1995 et 2006-2009 révèle une nette tendance à la simplification des successions, liée notamment à la réduction du nombre d'espèces cultivées: pour représenter $50 \%$ des terres labourables, il faut prendre en compte 37 triplets de cultures en 1992-1995, alors qu'il n'en faut plus que 16 en 2006-2009. Parmi ces 16 triplets de cultures majoritaires, trois triplets basés sur la culture de colza (colza-blé-orge, blé-colza-blé et colzablé-blé) sont en forte progression (entre +2 et +4\%), alors que le triplet blé-pois-blé régresse de manière importante $(-4 \%)$ (figure 13 ). De façon plus générale, l'évolution des successions culturales reflète l'évolution de l'assolement du bassin: les successions à base de pois et de tournesol diminuent, voire disparaissent, et sont principalement remplacées par des successions à base de colza et par des successions céréalières (blé-blé-blé, blé-blé-orge, blé-orge-orge) ; les successions quadriennales de type pois-blé-betterave-blé sont souvent remplacées par des successions plus courtes de type « tête de rotation-blé-blé » ou « tête de rotation-blé-orge ».

La simplification et le raccourcissement des successions culturales prennent des formes différenciées selon leur localisation dans le bassin de la Seine. La progression de la rotation colza-blé-orge, même si elle concerne quasiment l'ensemble du territoire, est surtout marquée dans sa partie est, en particulier sur les plateaux du Barrois et de la Bourgogne et dans le département de I'Yonne (figure 14). De manière complémentaire, la succession colza-blé-blé progresse essentiellement dans

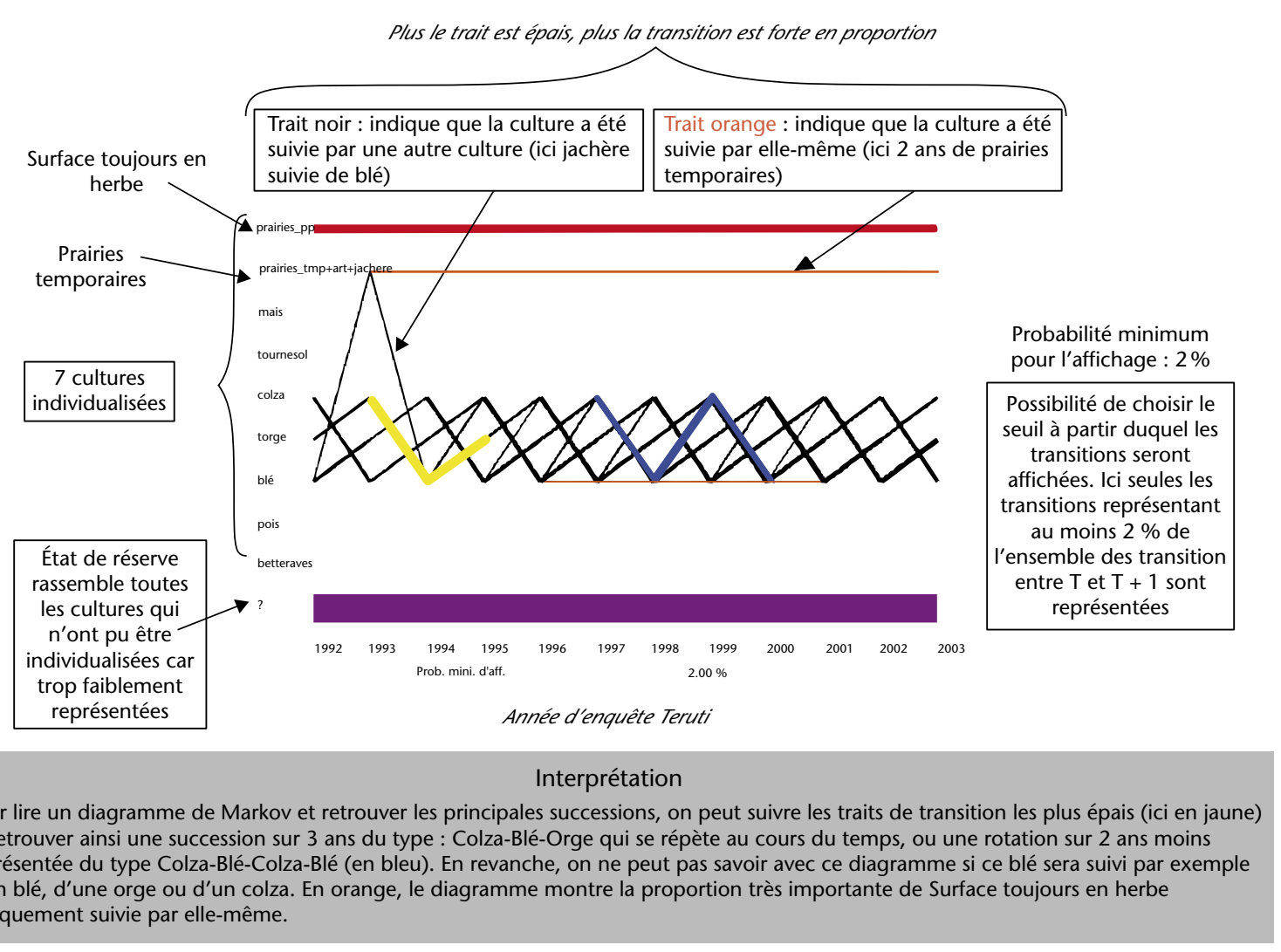

Figure 11. Principales transitions entre cultures sur la région agricole du Barrois (source : enquête Teruti 1992-2003). 


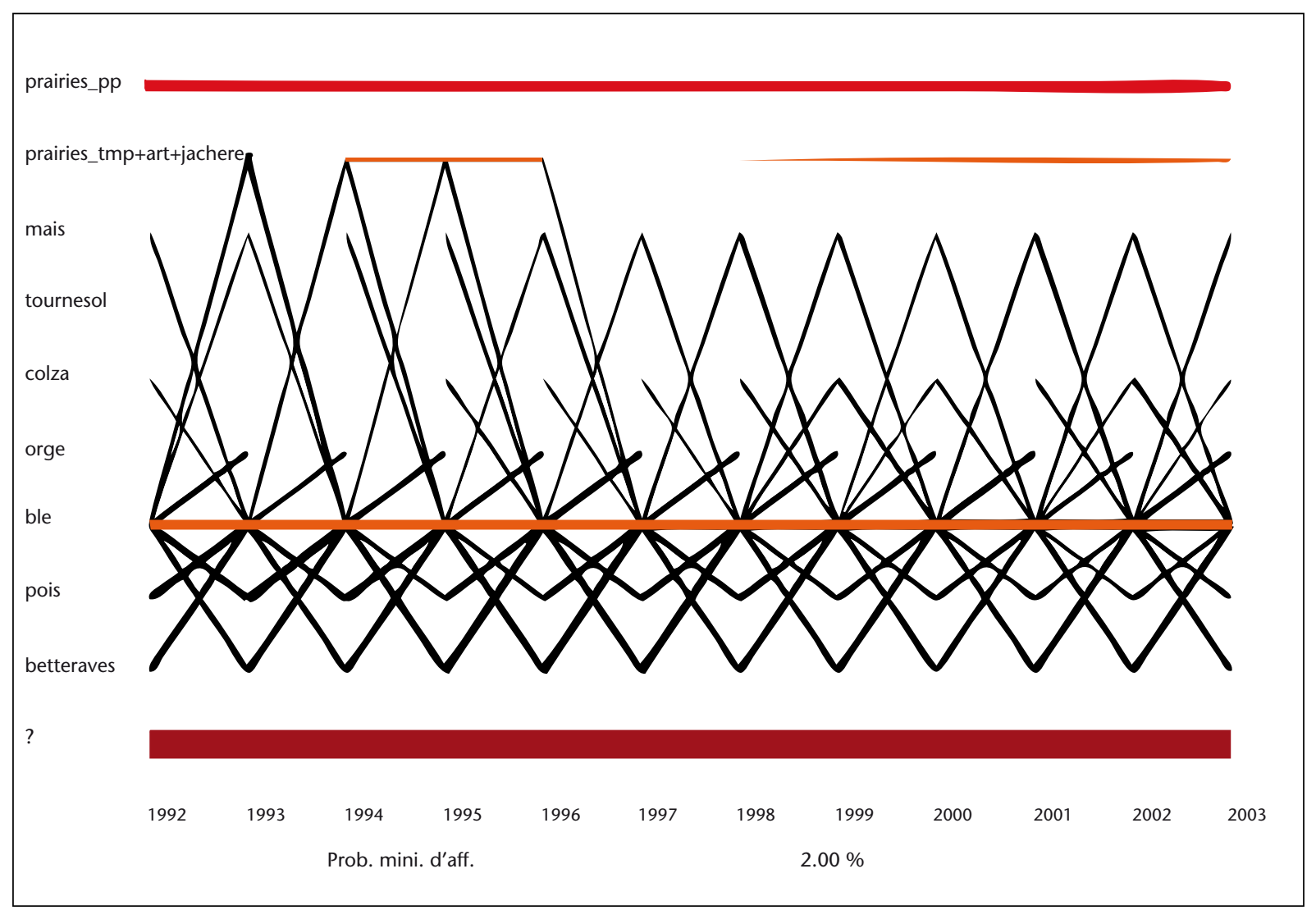

Figure 12. Principales transitions entre cultures sur les régions agricoles du Plateau Picard et du Vexin (source : enquête Teruti 1992-2003).

l'ouest du bassin, notamment dans les plaines de Beauce. La monoculture de blé montre une forte augmentation dans le nord-ouest du bassin, tandis que la succession blé-blé-orge progresse de manière plus ubiquiste.

\section{Évolution des successions de cultures permise par l'augmentation de l'usage des pesticides}

De manière générale, le raccourcissement des successions culturales favorise le parasitisme tellurique et les populations d'adventices. Par exemple, les difficultés de maîtrise des maladies cryptogamiques et, surtout, des graminées adventices, dans les monocultures de céréales, sont bien connues. De la même façon, la concentration des surfaces de certaines espèces accroît les risques de développement d'épidémies de parasites à dissémination aérienne. Il est clair que l'évolution des assolements et des successions que nous venons de décrire n'aurait pas été possible sans la batterie de spécialités pesticides, aujourd'hui disponible.

Les résultats de l'enquête "Pratiques culturales » de 1994, 2001 et 2006 sur le bassin de la Seine permettent de l'illustrer. La figure 15 montre ainsi l'évolution du nombre de traitements herbicides effectués sur colza: on observe une progression sur l'ensemble du bassin entre 1994 et 2001 parallèlement à la progression des surfaces en colza (figure 7), puis une concentration de l'augmentation du nombre de traitements sur la frange est, où la culture du colza est la plus répandue, et où la succession courte colza-blé-orge a le plus progressé (figure 14). II semble ainsi que plus les surfaces en colza sont importantes dans l'assolement et plus chaque culture de colza reçoit de traitements herbicides. Cette relation est confirmée par la figure 16 qui montre, sur les données de 2001, une corrélation positive significative, sur l'ensemble des régions agricoles du bassin de la Seine, entre le pourcentage de colza dans la SAU d'une région et le nombre moyen de traitements herbicides effectués sur colza dans la même région. Des relations analogues sont observées pour le nombre moyen de traitements phytosanitaires sur colza et pour le nombre de traitements insecticides.

Ainsi, comme l'ont montré Meynard et Girardin (1992) sur le cas du blé d'hiver, les pesticides sont devenus les pivots des systèmes de culture. Ils ont permis aux agriculteurs $d^{\prime}$ augmenter la production par hectare et la productivité du travail, mais ils ont aussi permis de raccourcir les rotations et facilité la domination d'un petit nombre d'espèces, dont le colza, dans les assolements. Les rotations courtes, les paysages peu diversifiés sont fortement dépendants de l'utilisation de pesticides. Si on veut réduire l'emploi des pesticides en agriculture, comme nous y invitent le Grenelle de l'environnement et la pression de l'opinion, il sera indispensable de rediversifier les cultures et d'allonger les rotations (Butault et al., 2010).

\section{Pour conclure : \\ les tendances lourdes sont-elles réversibles?}

Peut-on rediversifier les cultures ? Il est clair que ce ne sera pas simple, tant les processus économiques poussent à la simplification des systèmes de production et à la spécialisation des territoires. Quand une culture est abandonnée dans une exploitation, c'est un savoir-faire qui disparaît, parfois des équipements spécifiques qui sont revendus. Si cet abandon touche de nombreuses exploitations, I'appareil industriel local se réorganise autour des productions dominantes, et le savoir technique des conseillers se tarit, faute d'être renouvelé par un contact direct avec les producteurs ou par des expérimentations locales. Les espèces qui occupent des faibles surfaces constituent des marchés peu porteurs pour les semenciers; elles sont moins sélectionnées, et leur différentiel 


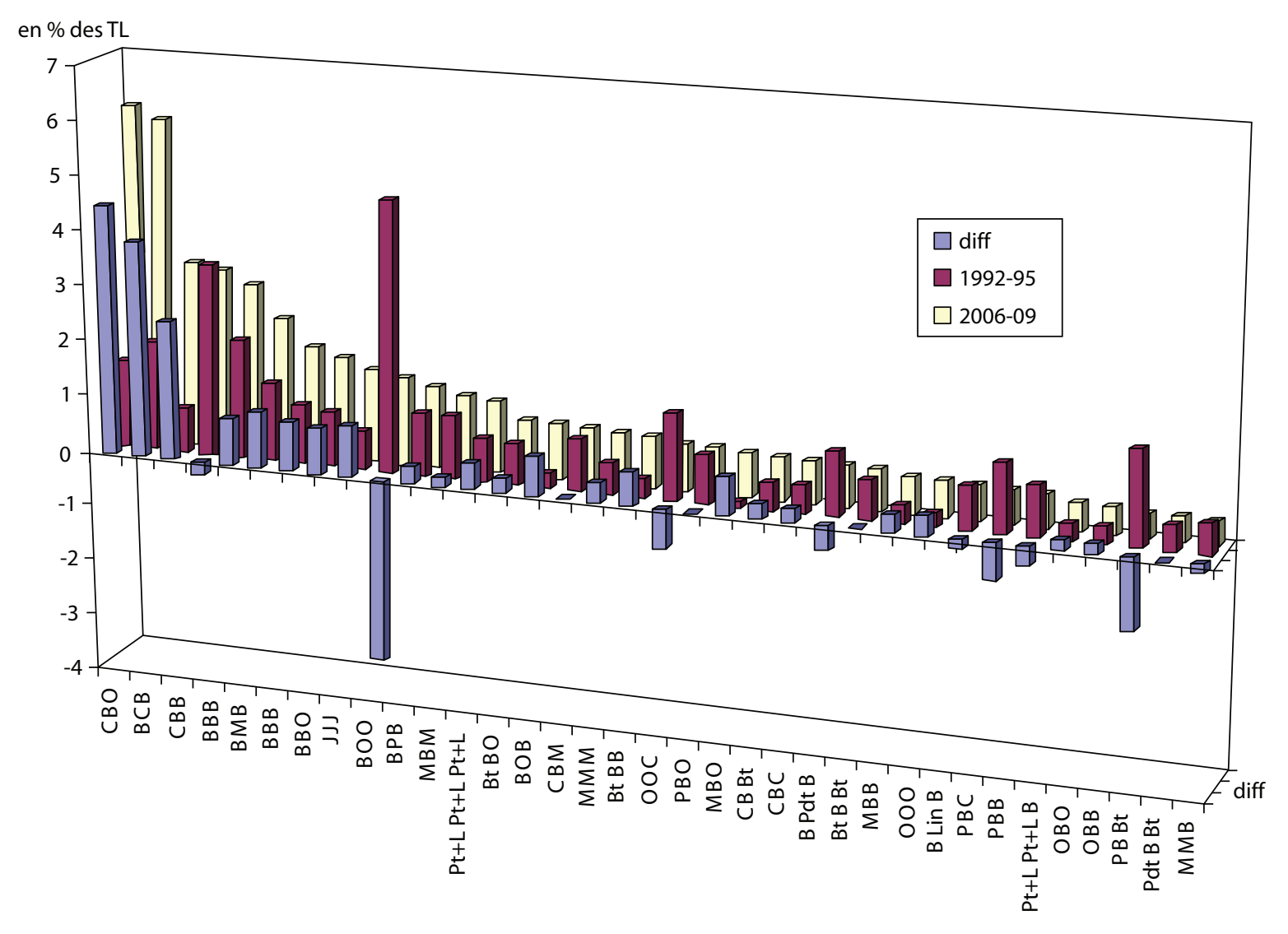

Figure 13. Évolution de la proportion des triplets de cultures majoritaires dans les terres labourables du bassin de la Seine entre les périodes 1992-1995 et 2006-2009 (source : enquête Teruti).

de productivité avec les espèces dominantes s'accroît (Lemarié, 2006). Le développement $d^{\prime}$ une nouvelle culture suppose en fait une action coordonnée au niveau de la sélection végétale, de l'élaboration de références, du développement de compétences techniques locales et de l'ouverture de marchés spécifiques. Ainsi, le redémarrage des protéagineux en 2010 suite à la mise en place d'un soutien public spécifique n'a été possible que parce que les sélectionneurs n'avaient pas abandonné le pois, que le savoir-faire des agriculteurs n'avait pas eu le temps de se perdre et que I'UNIP, Arvalis et I'INRA avaient continué à expérimenter et à proposer des innovations techniques. Mais quel sera l'avenir des protéagineux si la filière n'est pas stabilisée par la pérennisation de débouchés et par une reprise d'une activité intense de sélection variétale en Europe?

Pourtant, il y aurait de nombreux avantages à diversifier les cultures dans les successions et les paysages : pour limiter (on l'a vu) l'emploi des pesticides, ce qui ne peut qu'être bénéfique à la santé des écosystèmes et des agriculteurs; pour accroître l'hétérogénéité des mosaïques paysagères, favorable à la biodiversité en général, et aux oiseaux et petits mammifères en par- ticulier ; pour améliorer le bilan énergétique de l'agriculture, et réduire les émissions de gaz à effet de serre, grâce au développement spécifique de légumineuses; pour réduire les risques économiques liés aux systèmes trop spécialisés, dans un monde de plus en plus incertain (risques climatiques et instabilité des prix). Mais que pèsent ces avantages qui, pour la plupart, ne sont perceptibles ni à court terme ni à l'échelle de l'exploitation ? Le développement d'activités d'élevage dans les zones de grande culture favoriserait le recyclage local des éléments fertilisants et le développement de cultures favorables à l'environnement comme la luzerne, mais butte sur de nombreux obstacles, depuis la disparition des infrastructures de collecte de lait jusqu'aux réticences des résidents non agriculteurs à voir un élevage s'installer près de chez eux. Les systèmes de production agricoles et leur localisation apparaissent aujourd'hui comme totalement cohérents avec l'organisation de filières amont et aval et avec les systèmes de diffusion d'information. La stratégie de chaque acteur renforce la stratégie des autres et pousse à la spécialisation. On est dans un cas typique de ce que les chercheurs en sociologie et en éco- nomie de l'innovation appellent « verrouillage » ou lock-in (Liebowitz et Margolis, 1995, Cowan et Gunby, 1996). Personne en particulier ne " verrouille ", mais on a affaire à un système sociotechnique très cohérent, qui est le résultat de la remarquable réponse de l'agriculture française à l'injonction d'accroissement de la production de céréales et de sa compétitivité internationale (Butault et al., 2010).

Différentes expériences montrent que la diversification des cultures est possible au niveau de l'exploitation, sans baisse de marge : même si certaines cultures de diversification obtiennent des marges plus réduites, le résultat économique est équilibré au niveau de la rotation, grâce aux économies de pesticides et d'engrais azotés permises par les nouvelles cultures (Mischler et al., 2009). Pour que de telles expériences fassent tâche d'huile, une action volontariste des pouvoirs publics, étroitement coordonnée avec les acteurs des filières, apparaît indispensable. Une étude approfondie des conditions de réussite des opérations passées, ayant abouti au développement des nouvelles cultures ou productions, sera nécessaire pour définir les modalités précises que devra prendre l'action publique. Mais une prise de conscience collective de la situation actuelle 


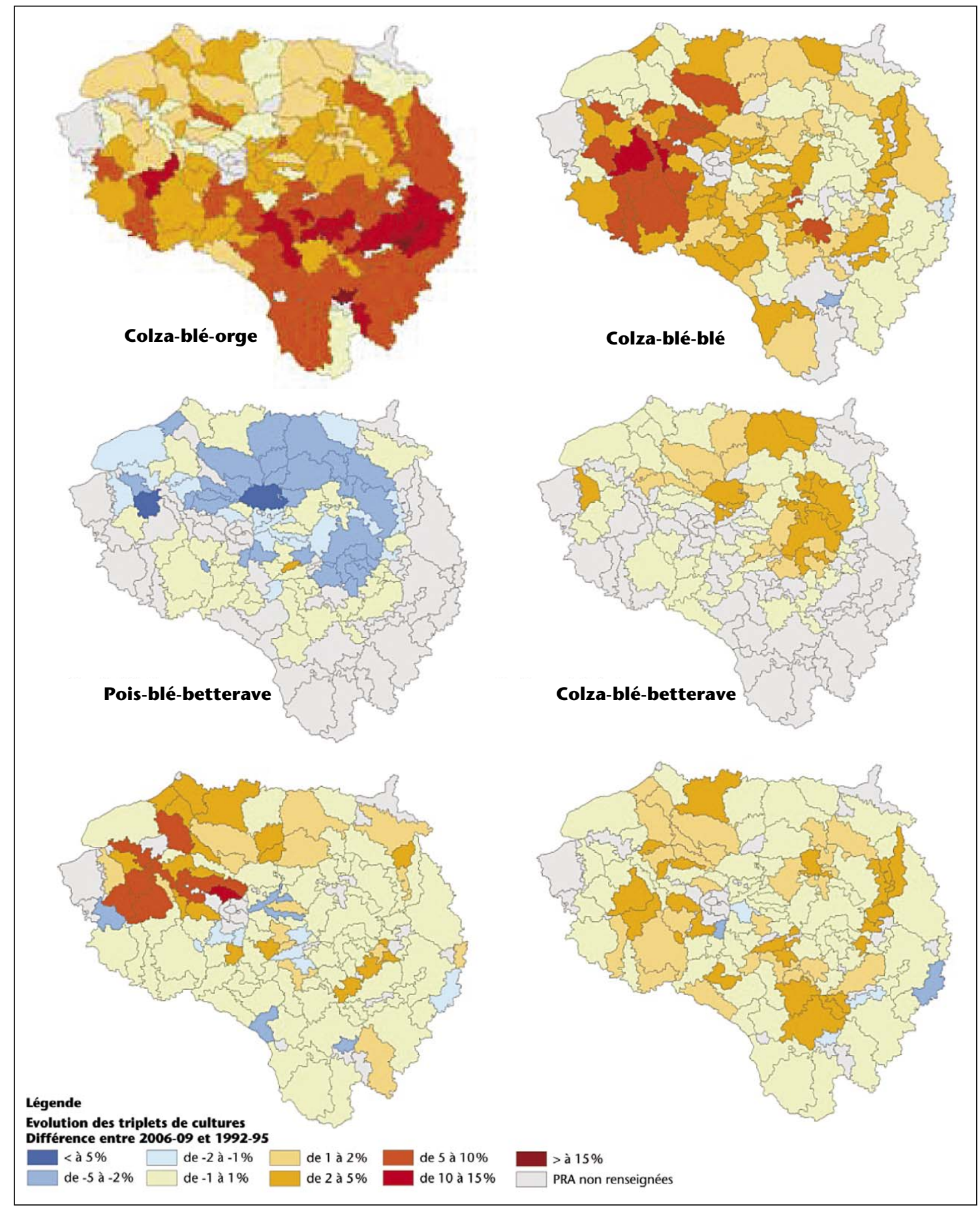

Figure 14. Évolution de la proportion de triplets de cultures dans les terres labourables du bassin de la Seine entre les périodes 1992-1995 et 2006-2009 (source : enquête Teruti). 


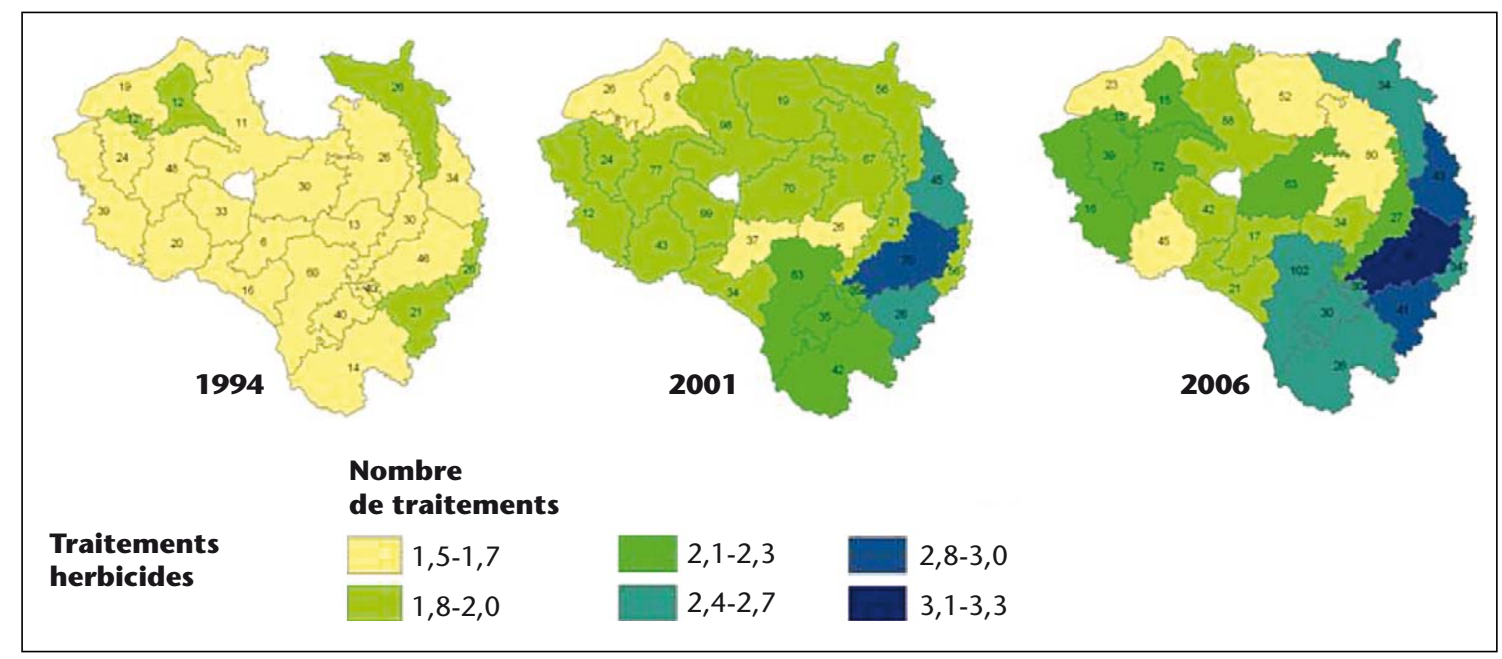

Figure 15. Évolution du nombre de traitements phytosanitaires sur la culture de colza d'hiver (source : enquête "Pratiques culturales sur grandes cultures » 1994, 2001 et 2006).

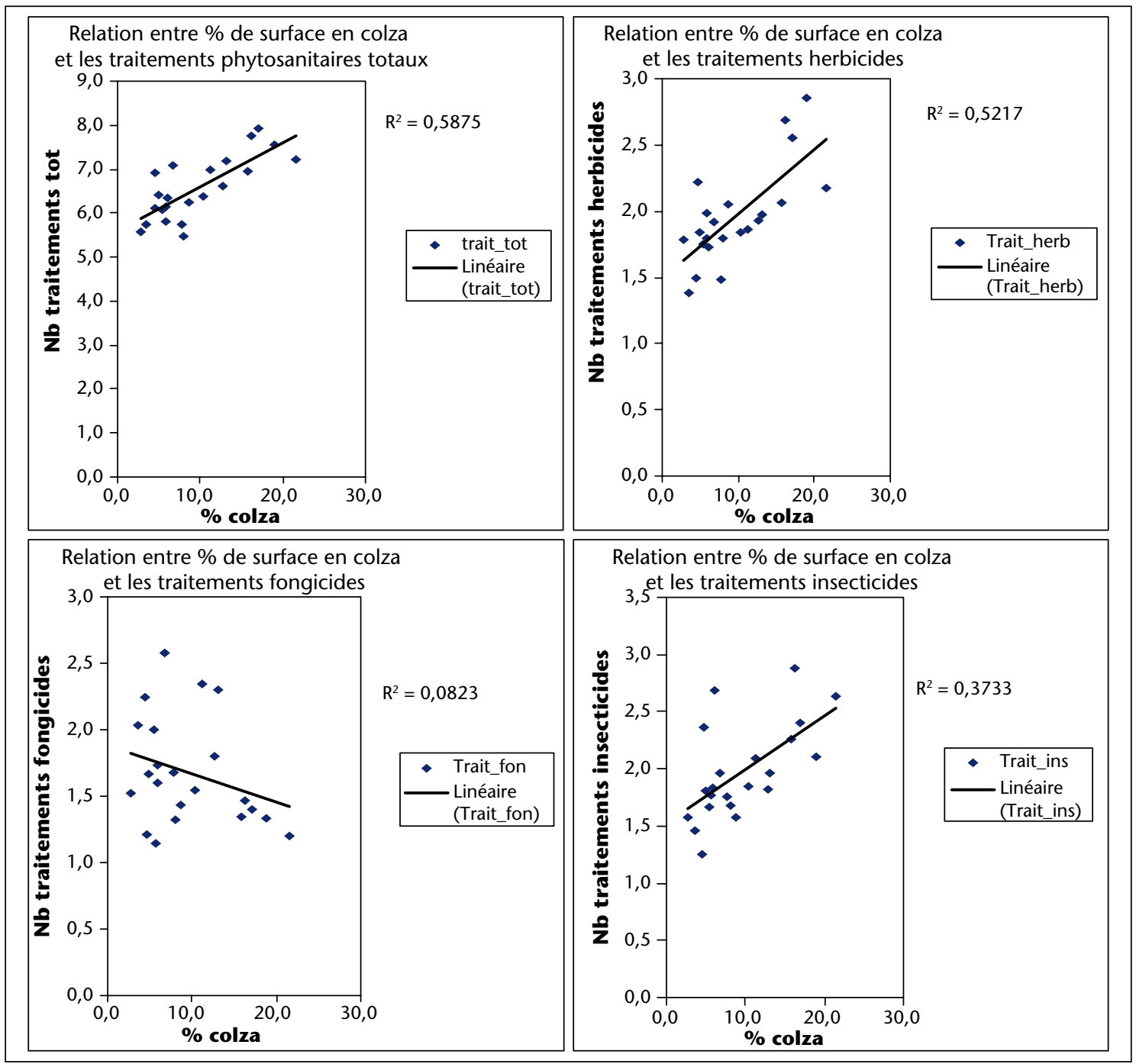

Figure 16. Nombre de traitements phytosanitaires selon le pourcentage de la surface en colza par grande région agricole du bassin de la Seine (source : enquête « Pratiques culturales sur grandes cultures » 2001 et RGA 2000). 
et de ses grandes tendances d'évolution est un préalable à cette mobilisation collective que nous appelons de nos vœux, faisant de la rediversification un objectif partagé par l'ensemble des acteurs de l'agriculture. Nous espérons, par cet article, y contribuer.

\section{RÉFÉRENCES}

Butault JP, Dedryver CA, Gary C, et al. Ecophyto $R \& D$, quelles voies pour réduire l'usage des pesticides. Synthèse du rapport d'étude. France: INRA éditeur 2010, 90 pages.

Cowan R, Gunby P. Sprayed to death: path dependence, lock-in and pest control. Econ / 1996 ; 106 : 521-43.

Le Ber F, Benoît M, Schott C, et al. Studying crop sequencies with CARrotAGE, a HMM-based data mining software. Ecol Modell $2006 ; 191$ : 170-85.
Lemarié S. Économie du secteur semencier au niveau international: échanges marchands, stratégies des firmes et du secteur public. In: Gasselin P, Clément O (coord.), Quelles variétés et semences pour des agricultures paysannes durables? Dossiers de I'Environnement de I'INRA, Paris, 2006; $30: 65-70$.

Liebowitz SJ, Margolis E. Path-dependence, lock-in and history. J Law Econ Organ 1995 ; 11 : 205-26.

Meynard JM, Girardin P. Produire autrement. Courrier de la cellule Environnement de L'INRA, $1992 ; 15$ : 1-19.

Mignolet C, Benoît M, Bornerand C. Différenciation du bassin de la Seine selon les dynamiques des systèmes de production agricoles depuis les années 1970. Cah Agric $2001 ; 10$ : 377-87.

Mignolet C, Schott C, Benoît M. Spatial dynamics of agricultural practices on a basin territory: a retrospective study to implement models simulating nitrate flow. The case of the Seine basin. Agronomie 2004 ; 24 : 219-36.
Mignolet C, Schott C, Benoît M. Spatial dynamics of farming practices in the Seine basin: methods for agronomic approaches on a regional scale. In: Billen G, Garnier J, Mouchel JM (eds) Human activity and material fluxes in a regional river basin: The Seine River watershed. Seine Special Issue. Science of the Total Environment 2007; 375 : 13-32.

Mischler P, Lheureux S, Dumoulin F, et al. Huit fermes de grande culture engagées en production intégrée réduisent les pesticides sans baisse de marge. Courr Environ $2009 ; 57$ : 73-91.

Schott C, Mignolet C, Benoît M. Agriculture du bassin de la Seine. Découvrir l'agriculture du bassin de la Seine pour comprendre les enjeux de la gestion de l'eau. Agence de l'Eau Seine-Normandie, Nanterre (FRA), 2009: 79 p. Téléchargeable sur le site du PIREN-Seine: http://www.sisyphe. upmc.fr/piren/webfm_send $/ 820$ 